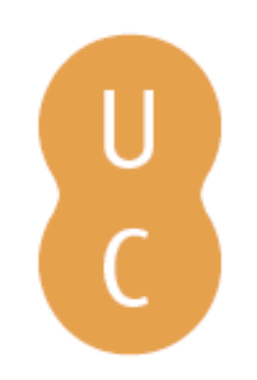

pnmbalina

\title{
Epígrafe votiva de Arronches, notícia da sua identificação
}
Autor(es):
Carneiro, André; d' Encarnação, José; Oliveira, Jorge de; Teixeira, Cláudia
Publicado por: Associação Portuguesa de Estudos Clássicos; Centro de Estudos
$\begin{array}{ll}\text { URL } & \text { URI:http://hdl.handle.net/10316.2/31544 } \\ \text { DOI: } & \text { DOI:http://dx.doi.org/10.14195/978-989-8281-69-2_7 }\end{array}$
Accessed : $\quad$ 26-Apr-2023 14:48:40

A navegação consulta e descarregamento dos títulos inseridos nas Bibliotecas Digitais UC Digitalis, UC Pombalina e UC Impactum, pressupõem a aceitação plena e sem reservas dos Termos e Condições de Uso destas Bibliotecas Digitais, disponíveis em https://digitalis.uc.pt/pt-pt/termos.

Conforme exposto nos referidos Termos e Condições de Uso, o descarregamento de títulos de acesso restrito requer uma licença válida de autorização devendo o utilizador aceder ao(s) documento(s) a partir de um endereço de IP da instituição detentora da supramencionada licença.

Ao utilizador é apenas permitido o descarregamento para uso pessoal, pelo que o emprego do(s) título(s) descarregado(s) para outro fim, designadamente comercial, carece de autorização do respetivo autor ou editor da obra.

Na medida em que todas as obras da UC Digitalis se encontram protegidas pelo Código do Direito de Autor e Direitos Conexos e demais legislação aplicável, toda a cópia, parcial ou total, deste documento, nos casos em que é legalmente admitida, deverá conter ou fazer-se acompanhar por este aviso.

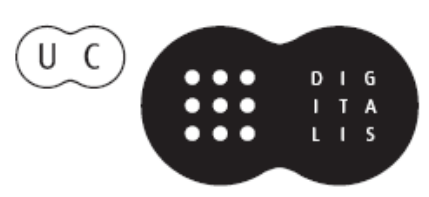




\section{Espaços e Paisagens}

Antiguidade Clássica

e Heranças Contemporâneas

Vol. III

Francisco Oliveira, Jorge Oliveira e Manuel Patrício

IMPRENSA DA UNIVERSIDADE DE COIMBRA 


\title{
EPÍGRAFE VOTIVA DE ARRONCHES NOTÍCIA DA SUA IDENTIFICAÇÃO
}

\author{
ANDRÉ CARNeiro \\ JosÉ D'ENCARNAÇÃO \\ JORGE DE OLIVEIRA \\ Cláudia Teixeira \\ CEAUCP - Centro de Estudos Arqueológicos \\ das Universidades de Coimbra e Porto
}

\section{Résumé}

Le contact des Romains avec les indigènes, qui parlaient, bien entendu, un autre langage mérite, de plus en plus, l'attention des chercheurs, parce qu'on s'aperçoit qu'il y a eu de notables influences réciproques. L'inscription en langue dite «lusitanienne» trouvée à Arronches (Lusitania - ager Emeritensis?), dont la première étude on présente ici, atteste exactement l'adoption d'un rituel semblable à celui de la suovetaurilia, où sont invoquées des divinités indigènes connues (Banda, Reva, Munis, Cantibidona) et une autre dont on ne connaissait rien jusqu'à présent (Broeneia). La possibilité d'intégrer tous ces rituels dans le cadre de la transhumance antique est, à la fois, très vraisemblable et séduisant.

Mots-clé: divinités indigènes, langue «lusitanienne», transhumance à l'époque romaine.

Palavras-chave: divindades indígenas, língua «lusitana», transumância na época romana.

Antes de nos debruçarmos sobre a epígrafe romana recolhida no vale da Ribeira da Venda, a norte da vila de Arronches (Portalegre), na propriedade designada "Monte do Coelho", e de que tivemos conhecimento em meados de 2007, permita-se-nos que, para melhor se enquadrar o seu real interesse histórico, recordemos três premissas metodológicas:

1 - Os Estudos Clássicos, mesmo que entendidos apenas numa óptica literária, carecem de debruçar-se sobre as línguas que os Romanos encontraram nas zonas onde vieram a instalar-se. E, nesse aspecto, o conceito 
de "romanização" implica um olhar nos dois sentidos: romano / indígena / romano.

2 - A influência da oralidade foi, nesse contacto, muito mais sensível do que, a princípio, se pensava.

3 - O universo religioso detém, nesse domínio, bem relevante papel na compreensão da aculturação registada.

Acrescente-se que, na Lusitânia romana, das línguas dos povos indígenas pouco ou nada se conhece:

$\left.1^{\circ}\right)$ porque os indígenas, ao que parece, não tinham o hábito da escrita;

$2^{\circ}$ ) porque rapidamente se adaptaram aos esquemas formais latinos;

$3^{\circ}$ ) porque a chamada «escrita do Sudoeste», pesem muito embora as soluções que amiúde se apresentam como peremptórias e definitivas, continua um enigma por decifrar.

Há, contudo, um 'estrato linguístico' (digamos assim) que o saudoso Prof. António Tovar ousou designar de «lusitano», por apresentar características morfológicas e linguísticas singulares e individualizantes. Torna-se difícil determinar - por falta de elementos quer do contexto arqueológico quer de âmbito paleográfico - uma data mais ou menos precisa para essas inscrições, designadamente as que ocorrem em penedias; contudo, à que ora nos ocupa, uma cronologia de primórdios do século I da nossa era ou mesmo de finais do século I a. C. afigura-se-nos muito plausível, atendendo, de modo especial, à paleografia e ao modo de identificação dos possíveis antropónimos e dos teónimos (já conhecidos doutras epígrafes).

Um dos textos estudados por António Tovar - e sobre o qual muitos outros autores se têm debruçado - é o do penedo de Lamas de Moledo, concelho de Castro Daire ${ }^{1}$. Uma das suas interpretações plausíveis:

RVFINVS. ET
TIRO SCRIP
SERVNT
VEAMINICORI
DOENTI
AN(?)COM
LAMATICOM
CROVGEAI MAGA
REAICOI. PETRANIOI. T

${ }^{1}$ Cf., sobre estas epígrafes, entre outros, os seguintes estudos (que indicam bibliografia anterior): Jürgen Untermann 2002; F. Patrício Curado 2002 e J. L. Inês Vaz 1989. 
ADOM. PORGOM INOVEA

.CAIELOBRIGOI

É esta uma tradução aceitável, ainda que não isenta de muitas dúvidas:

«Rufino e Tirão escreveram: os Veaminicórios oferecem 'ancom lamaticom' a Crouga, protectora dos Magariaicos; os Petrânios, um porco 'tadom' a Ióvea, protectora dos Caielóbrigos».

Num outro penedo, em Cabeço das Fráguas (Pousafoles, Sabugal), lê-se:

OILAM. TREBOPALA.

INDI. PORCOM. LABBO.

COMAIAM. ICCONA.LOIM

INNA. OILAM. VSSEAM.

TREBARNVE. INDI.TAVROM

IFADEM

REVE. $\underline{R E}$...

De acordo com as interpretações mais correntes, estaríamos, aqui, perante a oferta de um cordeiro a Trebopala; de um leitão a Laebo; de uma vitela (?) a Iccona Loimina; de um cordeiro de um ano a Trebaruna; e de um touro semental a Reva.

Como se verá, a epígrafe de Arronches situa-se no mesmo horizonte cultural e religioso, não só porque também aí se revela o sacrifício de animais a divindades, mas sobretudo porque é recorrente a palavra oilam, interpretada como variante 'interpretada' de oviculam, tal como porcom sem dificuldade se poderá considerar variante de porcum; e porque há referência a divindades indígenas conhecidas doutros ex-votos.

As epígrafes de Arroyo de la Luz (Cáceres) ${ }^{2}$ inserem-se também no mesmo plano, ainda que, por se ter perdido a mais antiga referenciada, só conhecida através de uma cópia de finais do século XVIII, e por serem fragmentárias as outras, não seja possível estabelecer um paralelismo tão evidente.

O monumento de Arronches é uma laje de grauvaque, cuja superfície epigrafada terá sido previamente alisada para receber a epígrafe, mantendo-se, porém, a irregularidade do conjunto. Podem causar alguma estranheza as suas dimensões $-88 \mathrm{~cm}$ de altura, 75 de largura e, de modo especial, a sua escassa espessura: $3,5 \mathrm{~cm}$. Certo é que, quando dela tivemos conhecimento, já ela fora reutilizada numa lareira; o proprietário, ao remodelar a casa, considerou que a laje ficaria bonita montada na fachada da casa e não a destruiu. Quando um de nós (JO) foi alertado para a descoberta, conseguiu convencer o proprietário a não a incrustar na parede, permitindo, assim, o seu estudo - o que penhoradamente agradecemos. Fica-nos, porém, a dúvida se, com essas reutilizações e considerando a facilidade com que o grauvaque se 'corta', a

\footnotetext{
${ }^{2}$ Francisco Villar e Rosa Pedrero 2001.
} 
peça não teria originalmente uma espessura maior, até para ser mais fácil a gravação. A não ser que tivesse sido gravada num penedo donde, em seguida, foi cortada.

Lemos:

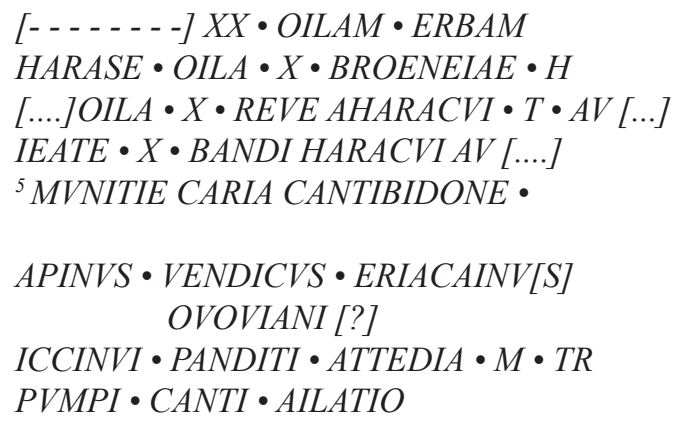

A paginação é cuidada, se atendermos, de modo especial, à regularidade dos espaços interlineares, à pontuação e ao cuidado posto na gravação (por goiva). O texto ocupa o espaço disponível no sentido da largura e, na altura, houve a preocupação de o situar na parte superior da laje, o que poderá indiciar que não seria para colocar em posição acima do olhar normal mas sim no solo. Há um espaço vazio entre as linhas 5 e 6, certamente para dar uma ideia de separação de conteúdos, o que é, para já, de muito realçar, uma vez que daí se depreende uma cultura epigráfica não despicienda.

Os caracteres - com 2,8 cm de altura média - são actuários e gravados com cuidado: barras horizontais breves; letras (como o A, o M, o N...) bem largas; $\mathrm{B}$ assimétrico e grafado em apenas dois movimentos; $\mathrm{P}$ aberto; $\mathrm{R}$ feito a partir do P.

Claro que importaria tecer considerações alargadas acerca das dificuldades de leitura e das várias hipóteses de interpretação. Deixamo-las para outra ocasião, limitando-nos, nesta notícia preliminar, a destacar dois ou três pontos que se nos afiguram de maior interesse imediato - pois temos a certeza de que, pelas inúmeras dúvidas que suscita, pelas novidades que traz em termos de designação de divindades e, até, de outra terminologia ainda por decifrar, esta epígrafe constitui, seguramente, um dos achados mais importantes dos últimos anos na epigrafia da Lusitânia romana.

Uma hipótese de interpretação poderá ser:

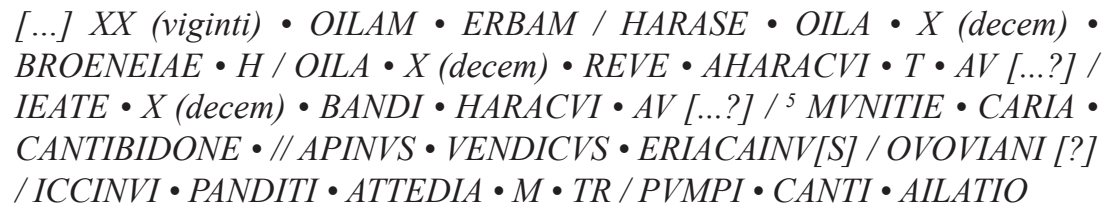


Poderia corresponder-lhe uma tradução deste género:

Para (...) vinte (...). Um cordeiro de erva para Harase. Dez cordeiros para Broineia H(arácua). Dez cordeiros para Reva Aharácuo. Dez T(?) AV(?) IEATE para Banda Harácuo. AV(?) para Municia Caria Cantibidone.

Os ovelheiros Apino, Vendico, Eriacno.

Revelai-nos a vossa vontade por um sinal.

Gravamos esta oração de júbilo.

A principal dificuldade reside, pois, no facto de todo o texto apresentar palavras estranhas ao vocabulário habitual em inscrições romanas, designadamente na sua segunda parte, sem dúvida a mais problemática, dado o seu teor. Se, por exemplo, ovoviani significar, como preconizamos, «ovelheiros», esse será, sem dúvida, um dado assaz interessante de todos os pontos de vista.

Reconhecemos, contudo, além da referida palavra oilam, teónimos como Reva, Banda e Munis (Broeneia é que jamais fora registada até ao momento) e poder-se-á afirmar, sem grande medo de errar, que se atesta aqui um ritual muito semelhante ao da suovetaurilia, sendo várias as divindades invocadas e sob um epíteto seguramente tópico, Haracui ou Aharacui ou mesmo Harase (numa diferença de grafia que outras vezes se documenta em relação às divindades indígenas, fruto do atrás referido 'contágio' da oralidade) ou, ainda, sob a forma da sigla H. De realçar, ainda, a novidade de nos parecer que o teónimo Munis vem grafado como Munitia e qualificado com dois epítetos, um (Caria) relacionável com outros teónimos indígenas, o segundo (Cantibidone) já documentado em relação a divindade conhecida, Erbina ${ }^{3}$.

Que significado atribuir a Haracui? A palavra hara poderá estar ligada ao mundo da pecuária: curral, chiqueiro de porcos; por outro lado, se apontarmos para um topónimo, torna-se aliciante 'encontrar' o termo na raiz semântica do nome da vila de Arronches! Como se sabe, de acordo com o Itinerário de Antonino, teríamos nestas zonas uma mansio: Ad Septem Aras... Estaria, sem dúvida, entre Arronches e Campo Maior, talvez por alturas de Degolados, onde importantes testemunhos da época têm sido encontrados ${ }^{4}$. E um pouco mais para oeste situa-se... Arronches!

Sugestiva é, ainda, essa perspectiva, se atentarmos numa eventual ligação com as rotas de transumância para a Beira Interior ${ }^{5}$, rotas que deixaram marcas

\footnotetext{
${ }^{3}$ HEp 4, 1994, inscrições n ${ }^{\text {os }} 1042-1043$.

${ }^{4}$ Cf. J. Alarcão 1992 (sobretudo p. 72) ou J. Alarcão 198899.

${ }^{5}$ Cf. J. Gómez-Pantoja 2001.
} 
toponímicas na paisagem arronchense, como "Canada"; ou, ainda, com a via atrás mencionada, de Emerita para Olisipo.

Mais as perplexidades, portanto, que as certezas. Mas destas há algumas que podemos garantir como dados verdadeiramente inovadores.

No que concerne à religiosidade pré-romana, dir-se-ia que a epígrafe figuraria num local aonde a população se ajuntava para honrar os seus deuses em determinadas épocas do ano, hipótese que também se coloca para Lamas de Moledo, Cabeço das Fráguas e para o altar identificado em Marecos (Penafiel), testemunho de um solene ritual agrário ligado ao ciclo da vegetação e da reprodução animal ${ }^{6}$.

Poderão ser referidas na epígrafe outras vítimas, mas a que não parece oferecer dúvida é o cordeiro, em número de dez (o que também constitui uma novidade) e, expressamente, uma vez indicado como erbam, ou seja, se a nossa interpretação está correcta, como já estando em idade de pastar (não apenas 'de leite').

No domínio da Linguística, escusado será sublinhar quanto esta epígrafe, por estar redigida em língua considerada «lusitana» e por, na verdade, se ler sem grandes dúvidas, vai contribuir para esclarecer questões em aberto.

Como fonte para os estudos históricos propriamente ditos, o facto de, desta sorte, como que se fechar, pelo Sul, a zona atribuída aos Lusitanos, na sequência do que temos vindo a afirmar sobre a presença de onomástica 'lusitana' no Nordeste alentejano ${ }^{7}$ - Lamas de Moledo a ocidente, Cabeço das Fráguas a norte, Arroyo de la Luz a oriente e Arronches a sul -, reveste-se, doravante, de importância relevante, a matizar o que Jorge Alarcão tem vindo a considerar o território deste "povo'8.

${ }^{6}$ Cf. HEp 1994, 6 n ${ }^{\circ}$ 1069, citando Patrick Le Roux (1994), «Cultes indigènes et religion romaine en Hispanie sous l'Empire», in L'Afrique, la Gaule, la Religion à l'Époque Romaine. Mélanges à la mémoire de Marcel Le Glay... Bruxelas 560-567. Pode ver-se a respectiva ficha in J. Cardim Ribeiro 2002 371, foto na p. 372.

${ }^{7}$ Cf. J. d'Encarnação 1987. 


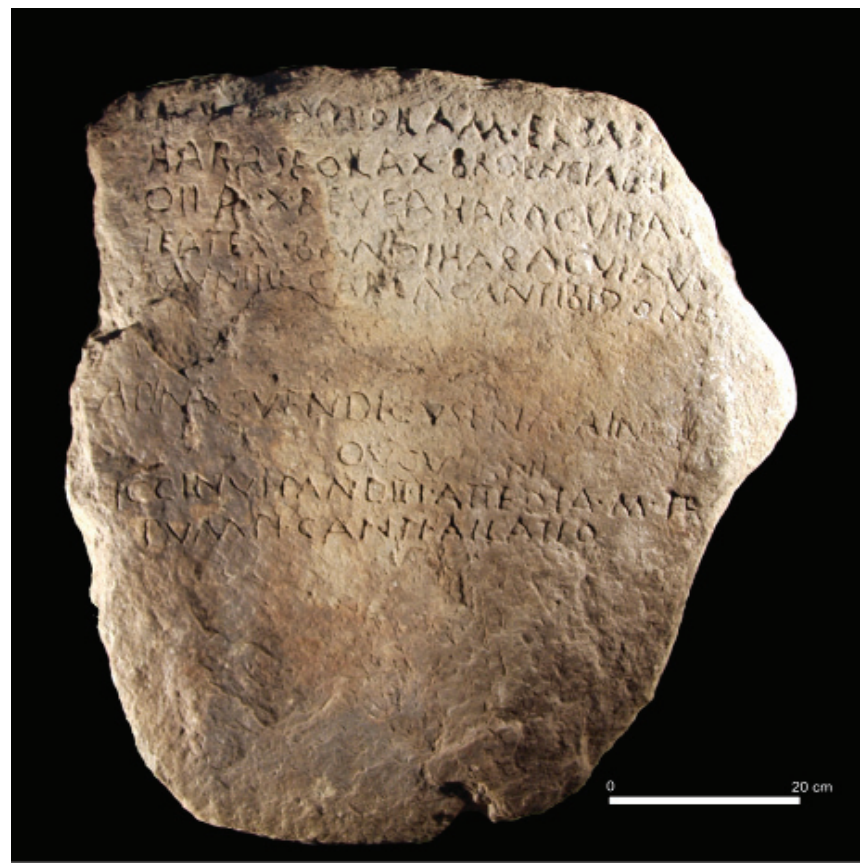

\section{Bibliografia}

J. Alarcão (1988), O Domínio Romano em Portugal. Mem Martins.

J. Alarcão (1992), “As estradas romanas de Portugal”, Encuentros sobre el Tajo: El Territorio y las Comunicaciones. Madrid, Cuadernos de San Benito 3 67-75.

J. Cardim Ribeiro, coord. (2002), Religiões da Lusitânia - Loquuntur Saxa. Lisboa, Museu Nacional de Arqueologia.

J. d'Encarnação (1987), "A população romana do Nordeste alentejano", in las Jornadas de Arqueologia do Nordeste Alentejano 85 - Actas. Castelo de Vide, 167-170.

J. Gómez-Pantoja (coord.) (2001), Los Rebaños de Gerion: Pastores y Trashumancia en Iberia Antigua y Medieval. Madrid, Casa de Velázquez. (1996), Hispania Epigraphica (=HEp) 6 nº 1069.

F. Patrício Curado (2002), «A "ideologia tripartida dos indoeuropeus" e as religiões de tradição paleohispânica no Ocidente peninsular», in J. Cardim Ribeiro, coord. (2002), Religiões da Lusitânia - Loquuntur Saxa. Lisboa, Museu Nacional de Arqueologia, 71-77.

J. Untermann (2002), “A epigrafia em língua lusitana e a sua vertente religiosa”, in J. Cardim Ribeiro, coord., Religiões da Lusitânia - Loquuntur Saxa. Lisboa, Museu Nacional de de Arqueologia, 67-70.

J. L. Inês Vaz 1989, "Divindades indígenas na inscrição de Lamas de Moledo (Castro Daire Portugal", Beira Alta 47.3-4 345-358.

F. Villar, R. Pedrero (2001), "La nueva inscripción lusitana: Arroyo de la Luz III", in Francisco

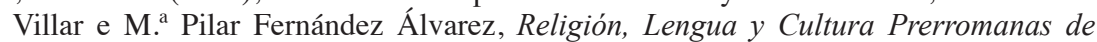
Hispania. Salamanca, 663-698. 